\title{
Investigation of strain rate sensitivity of Gum Metal under tension using digital image correlation
}

\author{
Karol Golasiński ${ }^{1}$ Elżbieta Pieczyska' ${ }^{1}$ - Michał Maj ${ }^{1} \cdot$ Maria Staszczak $^{1} \cdot$ Paweł Świec $^{2} \cdot$ Tadahiko Furuta $^{3}$. \\ Shigeru Kuramoto ${ }^{4}$
}

Received: 12 December 2019 / Revised: 6 April 2020 / Accepted: 25 April 2020 / Published online: 8 May 2020

(c) The Author(s) 2020

\begin{abstract}
Mechanical behavior of a multifunctional titanium alloy Gum Metal was investigated by conducting tensile tests at various strain rates and applying digital image correlation (DIC) technique. Stress-strain curves confirmed low Young's modulus and high strength of the alloy. The determined values of yield strength had a tendency to increase, whereas the elongation to the specimen rupture tended to decrease with increasing strain rate. True stress versus strain curves were analyzed using selected lengths of virtual extensometer (VE) placed in the strain localization area. When the initial length of the VE was the same as the gauge length, work hardening was observed macroscopically at lower strain rates, and a softening was seen at higher strain rates. However, the softening effect was not observed at the shorter VE lengths. Evolution of the Hencky strain and rate of deformation tensor component fields were analyzed for various strain rates at selected stages of Gum Metal loading. The DIC analysis demonstrated that for lower strain rates the deformation is macroscopically uniform up to the higher average Hencky strains, whereas for higher strain rates the strain localization occurs at the lower average Hencky strains of the deformation process and takes place in the smaller area. It was also found that for all strain rates applied, the maximal values of Hencky strain immediately before rupture of Gum Metal samples were similar for each of the applied strain rates, and the maximal local values of deformation rate were two orders higher when compared to applied average strain rate values.
\end{abstract}

Keywords Titanium alloy $\cdot$ Gum Metal $\cdot$ Strain rate sensitivity $\cdot$ Strain localization $\cdot$ Digital image correlation $\cdot$ Full-field deformation analysis

\section{Introduction}

New generation of multifunctional materials must possess a set of exceptional properties in order to meet the increasing requirements of cutting-edge solutions that are applied in a variety of technological areas. Recently, a class of $\beta$ titanium

Elżbieta Pieczyska

epiecz@ippt.pan.pl

1 Institute of Fundamental Technological Research, Polish Academy of Sciences, Pawińskiego 5B, 02-106 Warsaw, Poland

2 Institute of Materials Science, 75 Pułku Piechoty 1A, 41-500 Chorzow, Poland

3 Toyota Central Research and Development Laboratories, Inc., Nagakute, Aichi 480-1192, Japan

4 Department of Mechanical Engineering, College of Engineering, Ibaraki University, 4-12-1 Nakanarusawa, Hitachi 316-8511, Japan alloys called Gum Metal has drawn increasing attention because of their unique performance. Their superior properties including low Young's modulus combined with high strength, large range nonlinear reversible deformation and high plastic deformability without hardening were described for the first time in [1]. Gum Metal is also characterized by Elinvar- and Invar-like behaviors that ensure it is reliable to use at a wide range of temperatures and in extreme environments including outer space [1, 2]. Gum Metal can therefore be successfully used in many fields including the automotive, precision, robotic and sports equipment industries. The use of Gum Metal as a key component has driven the development of a large number of innovations that are reflected in various patents. The innovations include a turbofan gas turbine engine, pressure and mechanical sensors, a fluid conduit, valves and novel golf clubs. In addition, the absence of toxic elements in the composition of Gum Metal, its high biocompatibility and low Young's modulus value similar to bone make it a promising candidate for biomedical 
applications including endodontic instruments and spinal implant systems.

Typical chemical composition of Gum Metal is $\mathrm{Ti}-36 \mathrm{Nb}-2 \mathrm{Ta}-3 \mathrm{Zr}-0.3 \mathrm{O}$ (wt $\%$ ). The manufacturing process includes powder metallurgy followed by solution treatment with cold working that enables the production of large pieces of Gum Metal. The low Young's modulus of Gum Metal is related to the specific chemical composition that results in the low stability of the $\beta$ phase. The composition was dictated by ab initio calculations based on density functional theory as described in [3]. The ideal strength of Gum Metal calculated in the same study was in the order of the alloy tensile strength measured experimentally as shown in [4]. In contrast to conventional cold-worked alloys, Gum Metal was reported to exhibit high strength combined with good ductility. Initial microstructural observations revealed several features including distinct surface steps called "giant faults," plastic flow localization and "nanodisturbances," which cannot be associated with any conventional mechanisms of plastic deformation [5]. This led to a hypothesis for a dislocation-free mechanism of plastic deformation in Gum Metal suggested in [1].

The outstanding characteristics of Gum Metal were the motivation to start a research into the alloy. It was reported that cold working of Gum Metal induces a strong $\langle 110\rangle$ texture component [5] and causes the formation of nanometersized secondary phases, orthorhombic $\alpha^{\prime \prime}$ martensite [6, 7] and hexagonal $\omega$ phases in the alloy [8-10]. In [11], it was determined by high-resolution transmission electron microscopic observations that the average spacing of the nanometer-sized $\omega$ phase was $6 \mathrm{~nm}$ and resulted in effective trapping of dislocations. The clarification of mechanisms of nonlinear recoverable deformation, in particular during the superelastic cyclic deformation, was presented in [12]. The deformation mechanisms active in the superplastic-like behavior of Ti-Nb Gum Metal including an involvement of dislocations [13], dislocation channeling and stress-induced $\omega-\beta$ transformation [14], as well as the mechanism of twinning $[15,16]$ were studied and reported in the literature.

It was also demonstrated that cold rolling applied to the alloy results in the preferential growth of a specific variant of orthorhombic $\alpha^{\prime \prime}$ nanodomains [17]. Long-range martensitic transformation in Gum Metal under loading is suppressed by the local barrier of the domain structure caused by oxygen atoms resulting in the relatively large nonlinear recoverable deformation [18]. Microscopic study of Ti-Nb-Ta-Zr-O alloys focused on a role of trace oxygen for dislocation-free deformation was presented in [19]. An overview of microstructural features observed at various scales and final properties of Gum Metal was given in [20].

Research then focused on analyzing the thermal response of Gum Metal under loading using infrared thermography [21]. In the initial investigation presented in [22], it was demonstrated that after a drop of temperature, related to pure elastic deformation, the temperature of the specimen increases also within the recoverable strain of the alloy. This led to the conclusion raised in [21] and developed in [22] that the nonlinear recoverable deformation of Gum Metal is demonstrated by a dissipative behavior and must be associated with a different mechanism than the classical elastic stretches of atomic bonding. The analysis was confirmed by a more comprehensive further observation by using infrared technique and presented in [23]. The obtained results are consistent with the proposed mechanism of formation of orthorhombic $\alpha^{\prime \prime}$ nanodomains, via phase transition [11], related to heat production [23].

Another experimental approach used for deformation monitoring is the optical technique-digital image correlation (DIC), which measures displacement fields for further calculation of strain fields. DIC was also effective for imaging the nucleation and propagation of phases of transformations [24-28]. This method has not yet been used for a comprehensive characterization of Gum Metal, but it has been used successfully in studies of several alloys including Ti alloys under loading in particular the shape memory alloy NiTi [24-26], transformation-induced plasticity (TRIP) steel [27] and the Portevin-Le Chatelier effect in 5456 Al-based alloy [28].

In turn, damage resistance in Gum Metal was studied in [29] using a multiscale experimental approach and it was concluded that the increased ductility of Gum Metal was caused by the presence of crack blunting mechanisms. However, strain rate sensitivity is another important factor that should be investigated. Limited data on this topic are currently available. Mechanical behavior of extruded and equal-channeled angular pressed Gum Metal was investigated under quasi-static and high-strain-rate compression conditions [30]. It was found that Gum Metal under compression is sensitive to the strain rate and the plastic deformation of Gum Metal samples under dynamic loadings changes from stable and homogeneous mode to unstable and inhomogeneous mode. So far, the effect of strain rate on the tensile behavior of Gum Metal has not been analyzed.

The aim of this research is to investigate the effect of strain rate on Gum Metal deformation behavior, presenting development of the Hencky strain and deformation rate tensor fields. A comprehensive program of research will lead to a better understanding of the mechanical performance of Gum Metal. This is important for the application of this class of advanced titanium alloy to a variety of innovative engineering solutions.

\section{Materials and methods}

\subsection{Material fabrication and characterization}

Gum Metal with composition of Ti-23Nb-0.7Ta-2.0Zr-1.2O (at.\%) was fabricated by Toyota Central Research and 
Development Laboratories Inc. using a manufacturing process described in [1]. The process includes sintering at $1300{ }^{\circ} \mathrm{C}$ for $16 \mathrm{~h}$ in a vacuum of $10^{-4} \mathrm{~Pa}$, hot forging, solution treatment at $900{ }^{\circ} \mathrm{C}$ for $30 \mathrm{~min}$ and subsequent quenching in iced water. Then, an oxidized surface layer was removed and the material was cold-worked with further annealing. As-fabricated Gum Metal slices had a thickness of around $0.5 \mathrm{~mm}$.

The microstructure analysis was carried out using both optical and scanning electron microscopies (SEM). The samples of Gum Metal were polished using a conventional mechanical technique and were etched with an aqueous $10 \%$ $\mathrm{HF}+10 \% \mathrm{HNO}_{3}$ solution.

The image of Gum Metal sample from optical microscope is presented in Fig. 1. As it is seen, the grains of $\beta$-Ti phase are equiaxial and its size changes from dozens of micrometers up to approximately 200 micrometers.

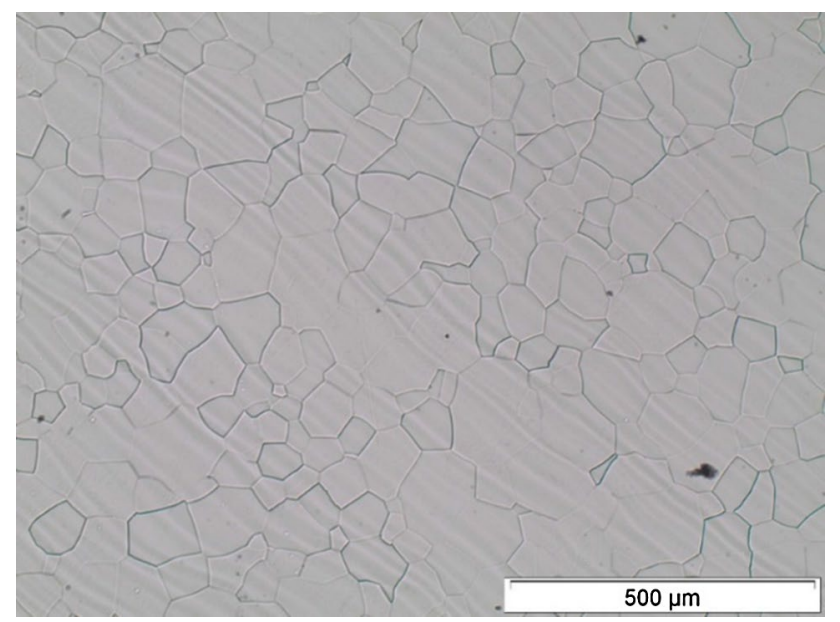

Fig. 1 Optical microscope image of Gum Metal
The texture analysis was carried out on a JEOL JSM6480 SEM equipped with a Nordlys II EBSD detector. The EBSD results were analyzed using Tango HKL software. The test was carried out at an accelerating voltage of $20 \mathrm{kV}$. The EBSD analysis was performed in order to determine the shape and size of grains and their potential preferred crystallographic orientation. The study confirmed that the sample had equiaxed grains with a $\beta$-Ti phase structure (Fig. 2). The shape of grain boundaries suggests large grains grow at the expense of small grains.

A histogram of the grain size distribution and the corresponding aspect ratios are shown in Fig. 3a, b, respectively. The average grain size is equal to $84.8 \mu \mathrm{m}$. The histogram of aspect ratios confirms that the grains are mostly equiaxial, i.e., its aspect ratio is close to 1 .

Pole figures showing a preferred crystallographic orientation in the sample of Gum Metal are shown in Fig. 4. As it is seen, no dominant texture component in Gum Metal can be observed.

Analysis of the chemical composition of Gum Metal was carried out using energy-dispersive $\mathrm{X}$-ray spectroscopy (EDS) on a JEOL JSM-6480 SEM. The study was carried out at an accelerating voltage of $20 \mathrm{kV}$ on selected material areas. An infrared Fourier transform spectrometer (IRFS) was used for the analysis. An example of the obtained EDS spectrum is shown in Fig. 5.

The analysis of chemical composition performed using EDS technique was carried out on 10 areas of the sample. The results are presented in Table 1.

The oxygen content could not be measured using this characterization technique. The chemical composition analyzed by EDS $\mathrm{Ti}-30 \mathrm{Nb}-1 \mathrm{Ta}-5 \mathrm{Zr}$ (wt\%) is slightly different than the nominal composition of Gum Metal Ti-36Nb-2Ta-3Zr-0.3O (wt\%). However, the EDS technique has a limited accuracy.
Fig. 2 Map of the crystallographic orientation of Gum Metal
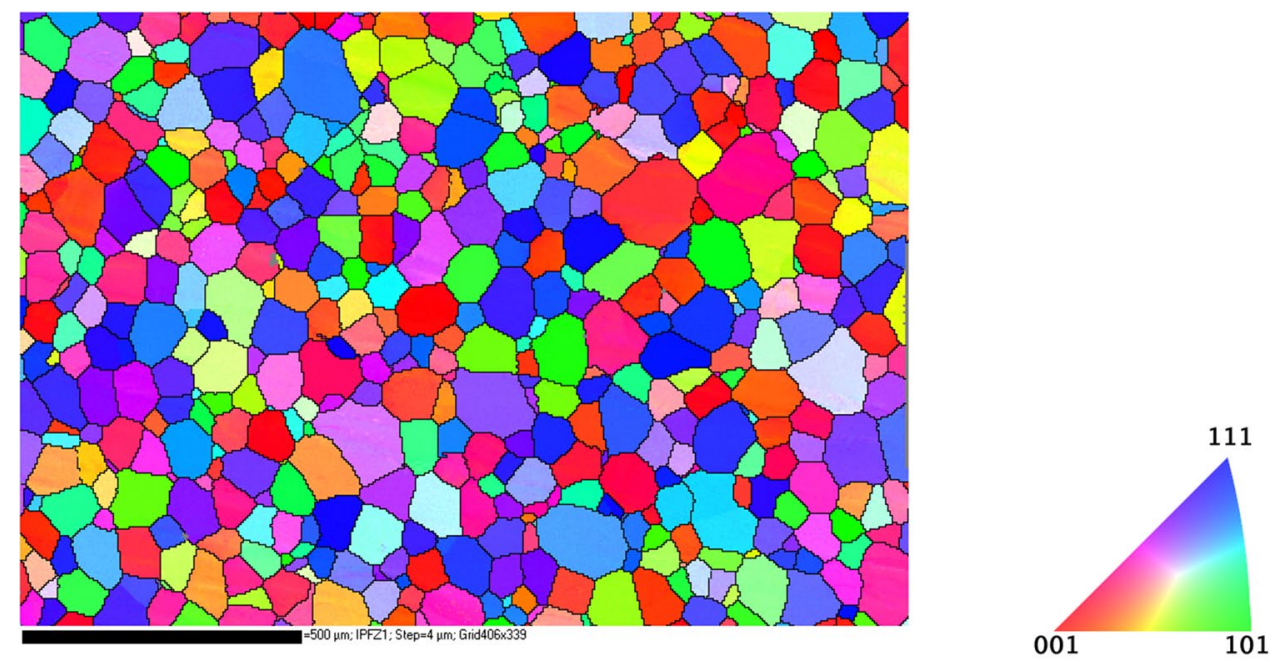

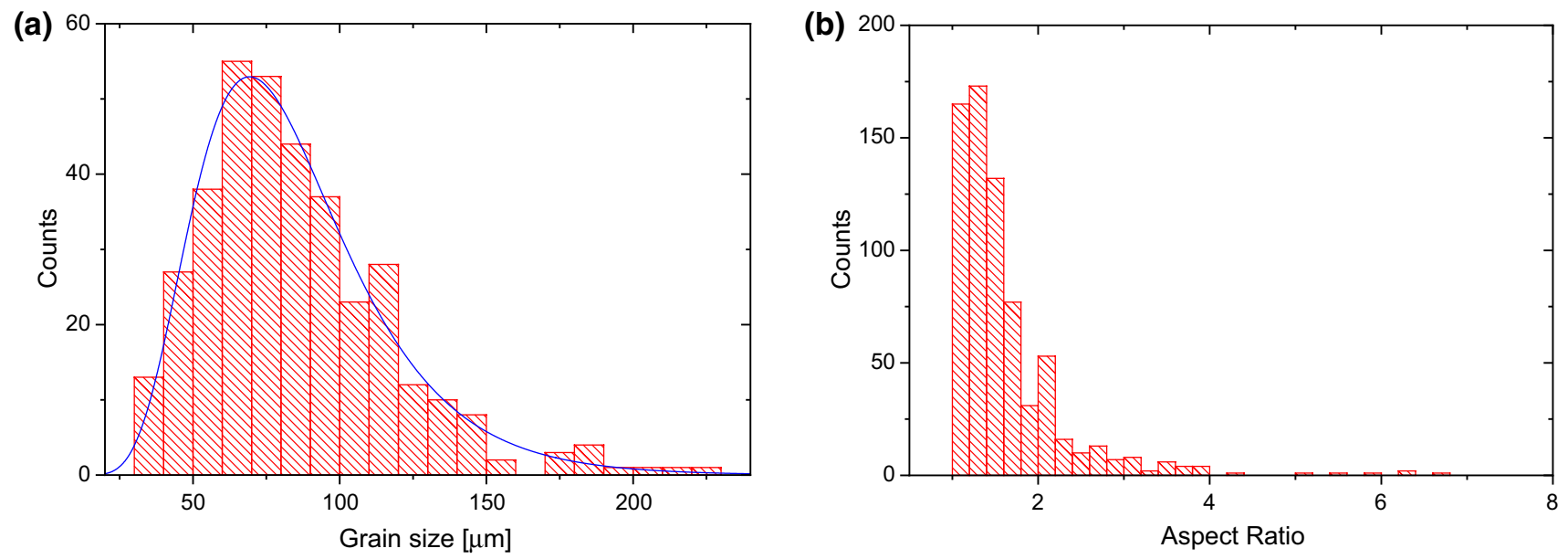

Fig. 3 a Histogram of grain size distribution, b corresponding histogram of grains aspect ratio

Fig. 4 Pole figures of Gum Metal

Fig. 5 Energy-dispersive X-ray spectroscopy spectrum of Gum Metal
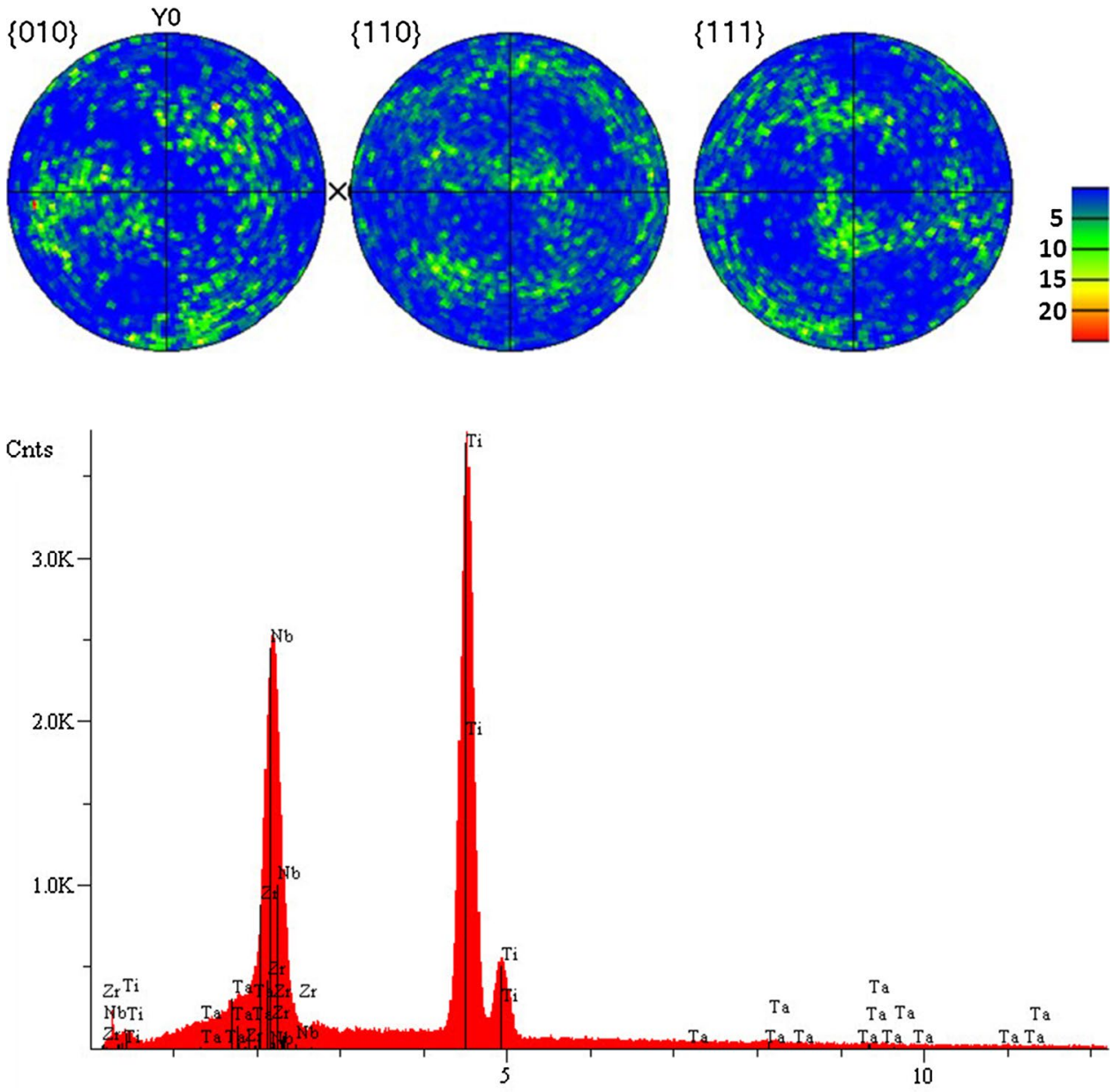

\subsection{Experimental details}

Gum Metal $0.5 \mathrm{~mm}$ slices were machined into flat samples with shape and sizes shown in Fig. 6a. A gauge area of the specimen ( $7 \mathrm{~mm} \times 4 \mathrm{~mm})$ was sprayed with small drops of white paint for DIC analysis (Fig. 6b).

Experimental setup used for the investigation of the mechanical response of Gum Metal under tension included a 
Table 1 Energy-dispersive X-ray analysis of the chemical composition of Gum Metal

\begin{tabular}{lllll}
\hline Spectra no. & \multicolumn{4}{l}{ Chemical composition (wt\%) } \\
\cline { 2 - 5 } & $\mathrm{Ti}$ & $\mathrm{Nb}$ & $\mathrm{Zr}$ & $\mathrm{Ta}$ \\
\hline 1 & $63.2(3)$ & $30.2(4)$ & $5.5(2)$ & $1.0(2)$ \\
2 & $63.4(3)$ & $30.1(4)$ & $5.5(2)$ & $1.0(2)$ \\
3 & $63.4(3)$ & $30.0(4)$ & $5.5(2)$ & $1.1(3)$ \\
4 & $63.7(3)$ & $30.4(4)$ & $5.0(2)$ & $0.9(2)$ \\
5 & $63.2(3)$ & $30.6(4)$ & $5.2(2)$ & $1.0(2)$ \\
6 & $63.4(3)$ & $30.4(4)$ & $5.3(2)$ & $0.9(2)$ \\
7 & $63.4(3)$ & $30.5(4)$ & $5.2(2)$ & $0.9(2)$ \\
8 & $63.0(3)$ & $30.7(4)$ & $5.2(2)$ & $1.1(2)$ \\
9 & $63.6(3)$ & $30.3(4)$ & $5.2(2)$ & $0.9(2)$ \\
10 & $63.5(3)$ & $30.1(4)$ & $5.2(2)$ & $1.2(2)$ \\
\hline
\end{tabular}

high-performance testing machine and a DIC system. A diagram of the experimental setup is shown in Fig. 7a. A photograph of the specimen placed in the grips of the testing machine is shown in Fig. 7b. During the tension process, the specimen of Gum Metal was monitored continuously by a visible range Manta G-125B camera. The camera resolution was $1100 \times 410$ pixels. A pixel size of $9.5 \mu \mathrm{m}$ and the maximal recording frequency of $58 \mathrm{~Hz}$ were used. Based on the acquired sequence of digital images, the evolution of the displacement distribution was determined. On the basis of the obtained displacement distributions, the Hencky strain and rate of deformation tensor components were calculated. ThermoCorr software with builtin implementation of 2D Digital Image Correlation algorithm developed in IPPT PAN was used. A detailed description of the applied DIC methodology is presented in [31].

\section{Results and discussion}

\subsection{Mechanical characteristics of Gum Metal under tension at various strain rates}

\subsubsection{Force versus displacement and true stress versus average Hencky strain curves}

To analyze the influence of strain rate on the mechanical behavior of the Gum Metal, tension tests up to the rupture were conducted at various strain rates. The Gum Metal samples were subjected to crosshead displacement controlled tension until rupture at five displacement rates: $0.00007 \mathrm{~mm} / \mathrm{s}, 0.0007 \mathrm{~mm} / \mathrm{s}, 0.007 \mathrm{~mm} / \mathrm{s}, 0.07 \mathrm{~mm} / \mathrm{s}$ and $0.7 \mathrm{~mm} / \mathrm{s}$. These values correspond to the average strain rates of $10^{-5} \mathrm{~s}^{-1}, 10^{-4} \mathrm{~s}^{-1}, 10^{-3} \mathrm{~s}^{-1}, 10^{-2} \mathrm{~s}^{-1}$ and $10^{-1} \mathrm{~s}^{-1}$ when specimen geometry is taken into account. The obtained force versus crosshead displacement curves are shown in Fig. 8a. Average Hencky strains $\bar{\varepsilon}_{y y}$ were calculated on the basis of displacement fields obtained by DIC using virtual
Fig. 6 a Shape, $\mathbf{b}$ surface of Gum Metal samples

Fig. 7 Experimental setup used for the investigation of Gum Metal under tension at various strain rates: a diagram, b photograph (a)

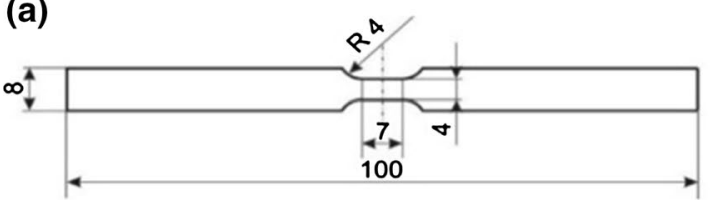

(b)

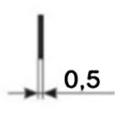

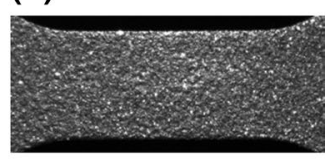

(a)

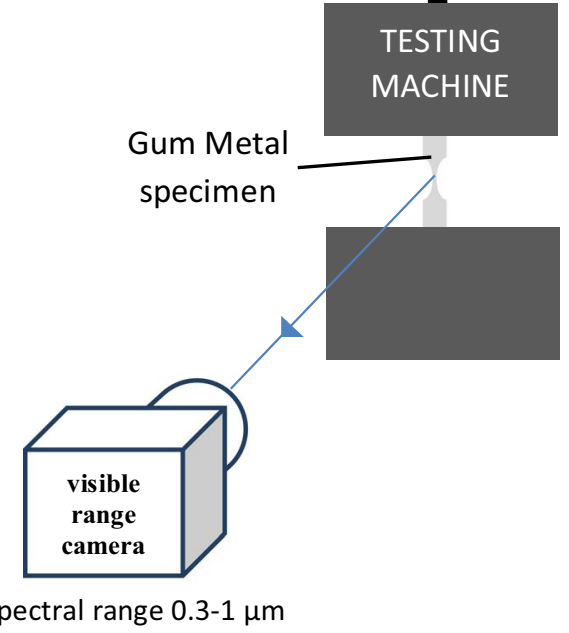

(b)

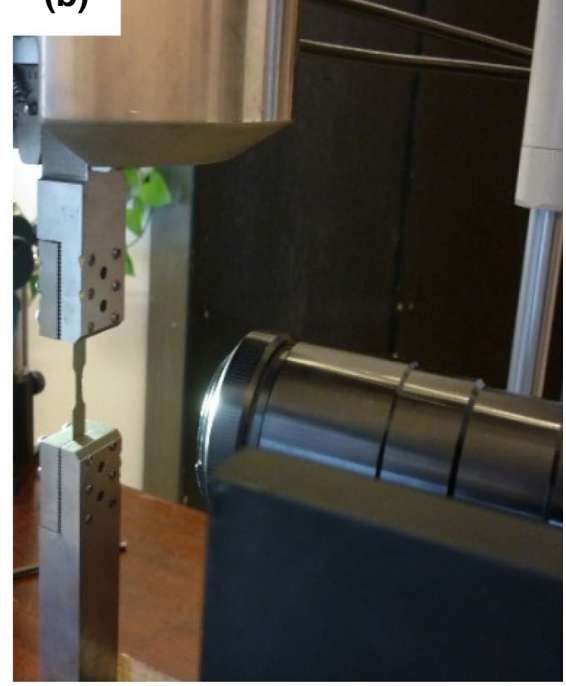


extensometers of two different lengths, i.e., $7 \mathrm{~mm}$ and $1 \mathrm{~mm}$. The results for the VE $7 \mathrm{~mm}$ and VE $1 \mathrm{~mm}$ placed in the localization area of the specimen are presented in Fig. 8b, c, respectively.

Analyzing Fig. 8, it can be seen that Gum Metal is very sensitive to the strain rate. It is worth noting that the mechanical characteristics presented in Fig. 8a, b show a similar tendency. True stress versus average Hencky strain curves reflect the macroscopic demonstration of the dependence, averaged by the VE $7 \mathrm{~mm}$ as shown in the diagram in Fig. $8 \mathrm{~b}$ and VE $1 \mathrm{~mm}$ as shown in the diagram in Fig. 8c. It is seen that the true stress versus average Hencky strain curves for the VE $7 \mathrm{~mm}$ obtained at strain rates $10^{-5} \mathrm{~s}^{-1}$, $10^{-4} \mathrm{~s}^{-1}$ and $10^{-3} \mathrm{~s}^{-1}$ show a macroscopically observed hardening effect, whereas those obtained at strain rates $10^{-2} \mathrm{~s}^{-1}$ and $10^{-1} \mathrm{~s}^{-1}$ demonstrate a macroscopically observed softening effect (see Fig. 8b). Drops in the loading force observed in Fig. 8a and drops in stress observed for the VE length $7 \mathrm{~mm}$ (equal to the gauge length of the specimen) shown in Fig. 8b demonstrate a sudden nucleation and development of strain localization. Thermal softening does not seem to occur, because Gum Metals are considered to be thermally stable. Nevertheless, local increase in temperature can be significant (up to $90{ }^{\circ} \mathrm{C}$ ) in the rupture area [23]. The softening effects are not observed in the case of VE equal to $1 \mathrm{~mm}$, as shown in Fig. 8c. It means that there is no softening of the material itself, but the effect caused by the understating the strain and consequently the stress values by assigning it to whole gauge part of the specimen, even if the deformation is localized in the narrow zone. Stress versus strain curves of Gum Metal under tension at different strain rates obtained by DIC for VE $1 \mathrm{~mm}$ were compared with a prediction based on a phenomenological hyperelastic-viscoplastic model in [32].

\subsubsection{Critical mechanical parameters of Gum Metal under tension at various strain rates derived from true stress versus average Hencky strain curves}

Determination of yield point in Gum Metal from the true stress versus average Hencky strain curve is not trivial because of its nonlinear superelastic-like deformation. In the case of conventional materials, when a yield point is not easily defined based on the shape of the true stress versus strain curve an offset yield point is arbitrarily defined. The value for this is commonly set at $\bar{\varepsilon}_{y y}=0.001$ or $\bar{\varepsilon}_{y y}=0.002$. The yield point determined using this method falls into the regime of plastic deformation of a given material. Nevertheless, Gum Metal is a material characterized by a nonlinear, mechanically reversible deformation. In previous works [23, 32], the range of mechanically recoverable strain of Gum Metal was determined during cyclic tension test and estimated to be around $1.4 \%$ of the
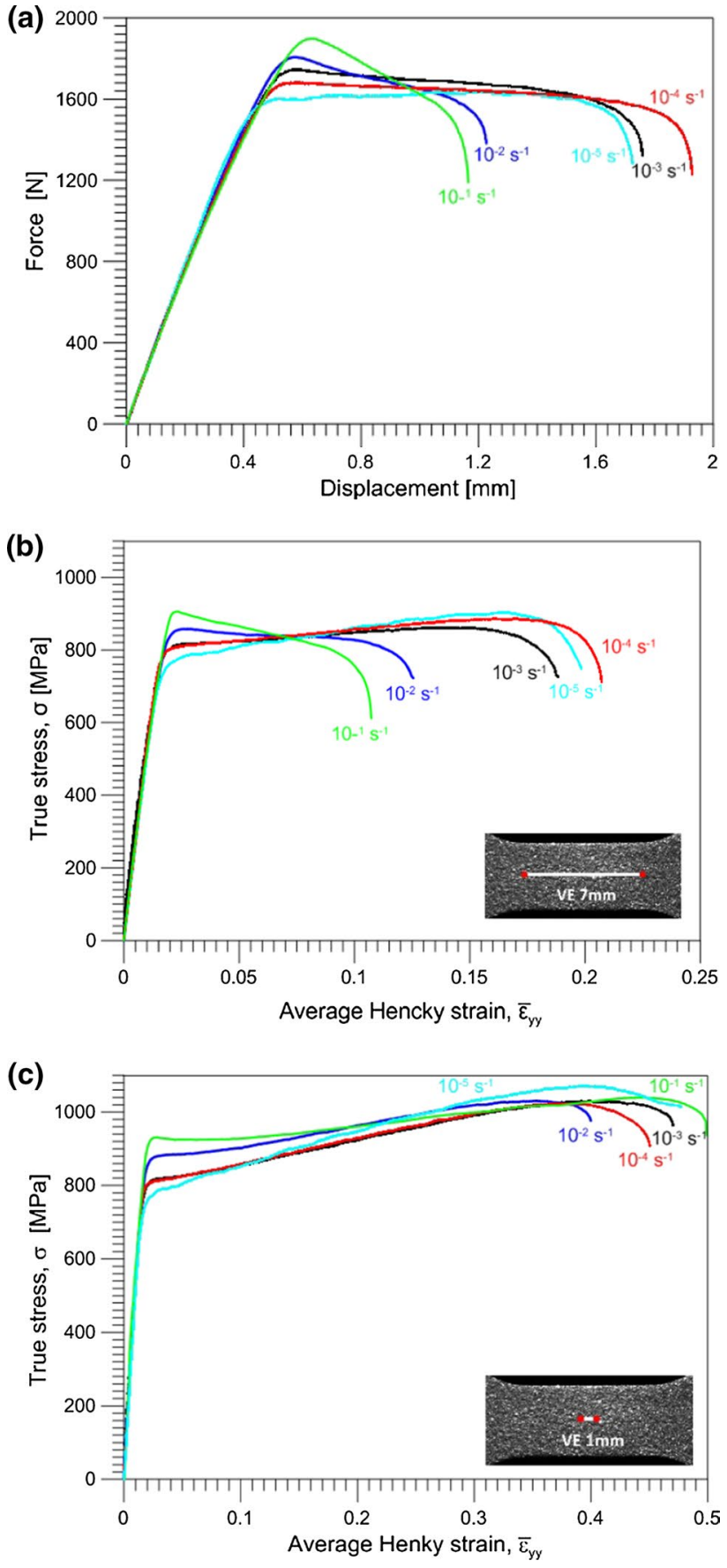

Fig. 8 Comparison of the mechanical characteristics of Gum Metal subjected to tension until rupture at strain rates: $10^{-5} \mathrm{~s}^{-1}, 10^{-4} \mathrm{~s}^{-1}$, $10^{-3} \mathrm{~s}^{-1}, 10^{-2} \mathrm{~s}^{-1}$ and $10^{-1} \mathrm{~s}^{-1}$ : a force versus displacement and true stress versus true strain curves for b VE $7 \mathrm{~mm}, \mathbf{c}$ VE $1 \mathrm{~mm}$

global strain, what corresponds to $\bar{\varepsilon}_{y y}=0.002$ taking into account the Gum Metal Young's modulus. Therefore, the offset yield point at $\bar{\varepsilon}_{y y}=0.004$ is chosen to make sure that the plastic (non-reversible) regime of Gum Metal is reached, as it is usually done in a case of conventional materials (Fig. 9). 


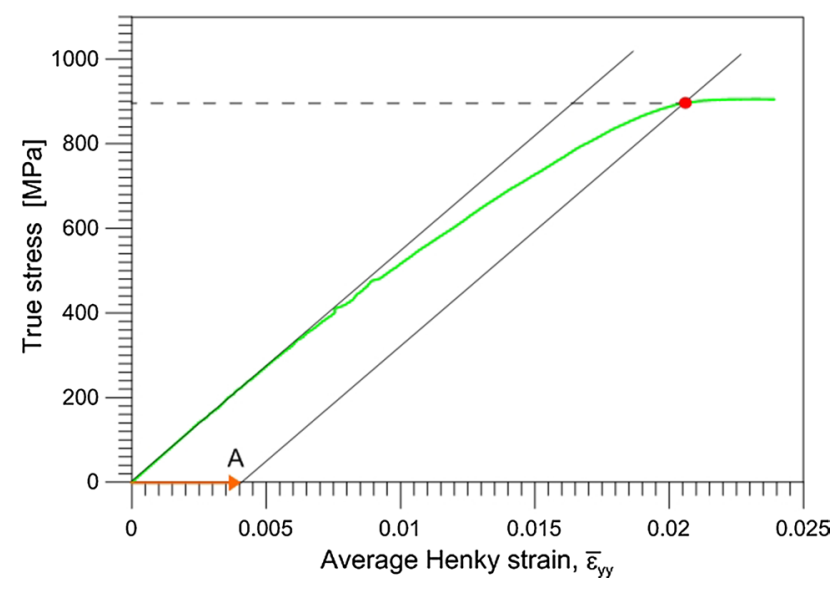

Fig. 9 Determination of yield point of Gum Metal using stress versus strain curve

Critical values of yield strength determined using the methodology presented in Fig. 9 and elongation to rupture of Gum Metal derived from the stress-strain curves for various strain rates calculated for the $7 \mathrm{~mm}$ VE length are listed in Table 2.

Values of yield strength increased with higher strain rates and varied from $741.32 \mathrm{MPa}$ obtained for the lowest strain rate $10^{-5} \mathrm{~s}^{-1}$ to $896.27 \mathrm{MPa}$ for the highest strain rate $10^{-1} \mathrm{~s}^{-1}$. Elongation, at which point rupture of the Gum Metal sample occurred, decreased with increasing strain rate. This rate ranged from 0.226 for the strain rate $10^{-4} \mathrm{~s}^{-1}$ to 0.107 for the strain rate $10^{-1} \mathrm{~s}^{-1}$. Therefore, the higher the strain rate, the lower the elongation to rupture. However, Fig. $8 \mathrm{~b}$ shows that at the lowest strain rate, $10^{-5} \mathrm{~s}^{-1}$, the strain range is lower than that obtained for the strain rate $10^{-4} \mathrm{~s}^{-1}$. At a low strain rate of $10^{-5} \mathrm{~s}^{-1}$, a creep-like deformation mechanism occurs, and this can play an important role in the loading and deformation process. A comparison of the critical mechanical properties of Gum Metal determined for various strain rates is presented in Table 2 . The yield strength and elongation to rupture versus strain rate are shown in logarithmic scale in Fig. 10a, b. It is seen that the yield strength of the Gum Metal increases, whereas the total elongation decreases with strain rate and the changes can be described by the logarithmic function.

Results obtained for different extensometer lengths show that at higher strain rates the strain localization process starts immediately after irreversible deformation occurs (Fig. 8b, c). It means that the true stress versus strain characteristics are not good measures of Gum Metal deformation and a full-field measurement approach using DIC technique would be better to understand and demonstrate the mechanical behavior of the alloy under loading.
Table 2 Comparison of yield strength and elongation to rupture of Gum Metal derived from the true stress versus strain curves obtained at five strain rates

\begin{tabular}{lccccc}
\hline Strain rate & $10^{-5} \mathrm{~s}^{-1}$ & $10^{-4} \mathrm{~s}^{-1}$ & $10^{-3} \mathrm{~s}^{-1}$ & $10^{-2} \mathrm{~s}^{-1}$ & $10^{-1} \mathrm{~s}^{-1}$ \\
\hline $\begin{array}{c}\text { Yield strength } \\
\text { (MPa) }\end{array}$ & 741.32 & 797.36 & 796.50 & 829.63 & 896.27 \\
$\begin{array}{l}\text { Elongation to } \\
\text { rupture }\end{array}$ & 0.197 & 0.226 & 0.188 & 0.125 & 0.107 \\
\hline
\end{tabular}

\subsection{Effect of strain rate on evolution of strain and deformation rate fields of Gum Metal under tension determined by DIC}

Based on the analysis of the stress-strain curves, the distributions of the Hencky strain $\boldsymbol{\varepsilon}$ and rate of deformation $\mathbf{D}$ tensor components were related to four critical stages of the Gum Metal tension:

1. $\bar{\varepsilon}_{y y}=0.015$-end of recoverable strain

2. $\bar{\varepsilon}_{y y}=0.030$ — around yielding

3. $\bar{\varepsilon}_{y y}=0.075$-advanced plastic deformation

4. $\bar{\varepsilon}_{y y \max }$-just before rupture.

The components of the Hencky strain tensor $\varepsilon$ were determined on the basis of the displacement gradient tensor $\mathbf{H}$ obtained from displacement field measured using 2D DIC method. In this case the $\mathbf{H}$ tensor has the following form:

$\mathbf{H}=\frac{\partial \mathbf{u}}{\partial \mathbf{X}}=\left[\begin{array}{ccc}\frac{\partial u_{x}}{\partial X} & \frac{\partial u_{x}}{\partial Y} & 0 \\ \frac{\partial u_{y}}{\partial X} & \frac{\partial u_{y}}{\partial Y} & 0 \\ 0 & 0 & {[\cdot]}\end{array}\right]$,

where $\mathbf{u}=\left(u_{x}, u_{y}\right)$ is the displacement vector and $\mathbf{X}=(X, Y)$ is a position of a material point in the Lagrangian coordinate system. The $\frac{\partial u_{z}}{\partial Z}$ component, which is not measured in $2 \mathrm{D}$ DIC analysis, was calculated under assumption of a constant volume. The detailed procedure of Hencky strain tensor $\boldsymbol{\varepsilon}$ determination is presented in [31]. An example of the DIC analysis applied for uniaxial tension and simple shear processes performed on austenitic steel 304L samples was presented in [33]. Digital image correlation and ultrasonic measurement were also used to investigate mechanical anisotropy of Gum Metal samples under compression in [34].

The rate of deformation tensor $\mathbf{D}$ was determined on the basis of the velocity field $\mathbf{v}$ as a symmetric part of the velocity gradient $\mathbf{L}$ :

$\mathbf{D}=\frac{1}{2}\left(\mathbf{L}+\mathbf{L}^{\mathbf{T}}\right)$,

where $\mathbf{L}=\frac{\partial \mathbf{v}}{\partial \mathbf{x}}$ and $\mathbf{x}=(x, y)$ is a position of a material point in the Eulerian coordinate system. 
(a)

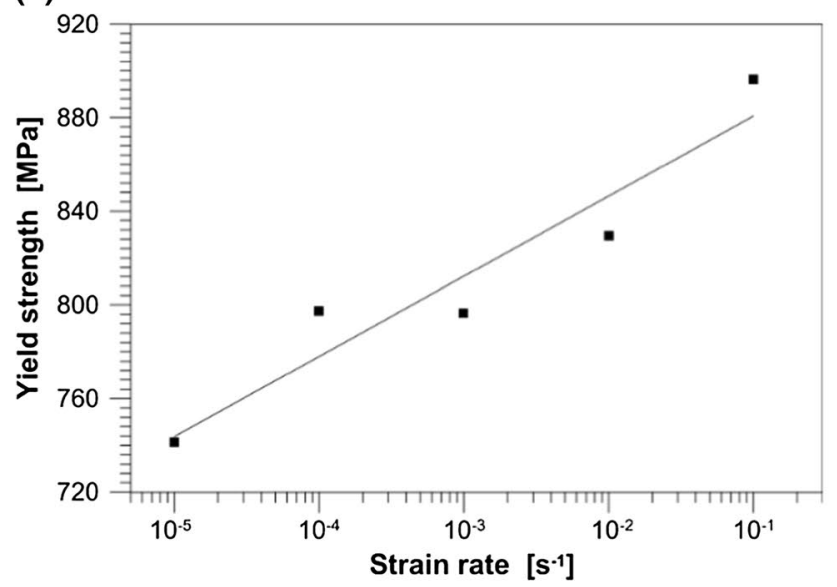

(b)

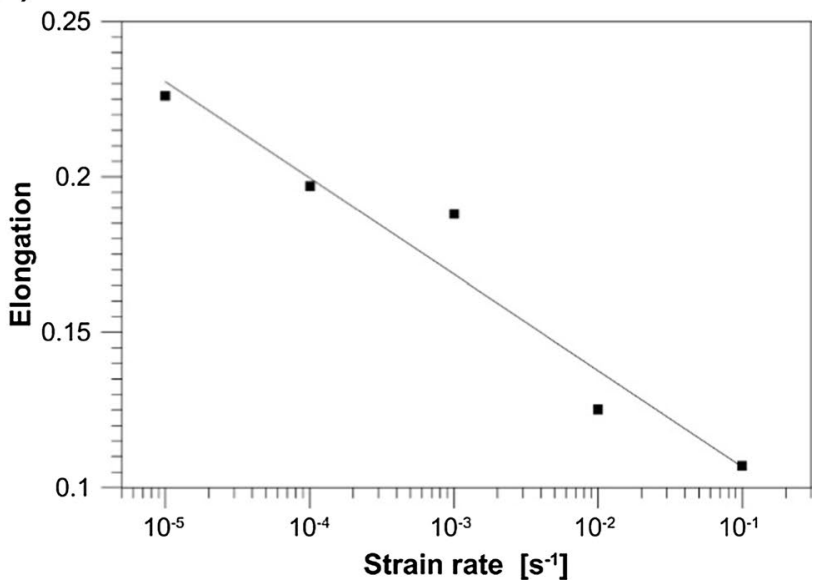

Fig. 10 Comparison of critical mechanical properties of Gum Metal: a yield strength, $\mathbf{b}$ elongation to rupture presented versus strain rate

Selected distributions of the $\varepsilon_{y y}$ and $D_{y y}$ components, where $\mathrm{y}$ is the tension direction, for strain rate of $10^{-1} \mathrm{~s}^{-1}$ at four selected stages are presented in Fig. 11.

\subsubsection{Development of Hencky strain $\varepsilon_{y}$ distributions}

Development of $\varepsilon_{y y}$ distributions obtained using the DIC algorithm for Gum Metal tension for different strain rates is shown in Fig. 12. In addition, profiles passing through a point with maximal value of $\varepsilon_{y y}$ and parallel to the loading direction $y$ are shown on the right of distributions captured at $\bar{\varepsilon}_{y y}=0.075$ and before rupture of the Gum Metal specimens.

Hencky strain $\varepsilon_{y y}$ distributions were quite homogenous and comparable at strains $\bar{\varepsilon}_{y y}=0.015$ and $\bar{\varepsilon}_{y y}=0.030$ for all strain rates. At strain $\bar{\varepsilon}_{y y}=0.075$, the strain localization was already visible for the higher strain rates $10^{-1} \mathrm{~s}^{-1}$ and $10^{-2} \mathrm{~s}^{-1}$ in contrast to that obtained for the lower strain rates of $10^{-3} \mathrm{~s}^{-1}, 10^{-4} \mathrm{~s}^{-1}$ and $10^{-5} \mathrm{~s}^{-1}$. Immediately before the rupture of the Gum Metal specimen, the strain localization was clearly defined for all strain rates and was accompanied by maximum local strains of approximately 0.5 as shown in the strain distributions and corresponding profiles for all strain rates. Development of strain localization was also confirmed by analysis of temperature distributions of Gum Metal specimen at selected stages of tension [23]. Rupture of Gum Metal specimen was accompanied with significant local temperature rise, up to $90{ }^{\circ} \mathrm{C}$ in the case of tension at strain rate $10^{-1} \mathrm{~s}^{-1}$ as shown in [23].

In order to analyze strain distributions more comprehensively, points from the localization zones with maximal values of $\varepsilon_{y y}$ (just before rupture) were selected and their time evolutions from the beginning of the loading process at various strain rates were analyzed. Their records in time during the process of tension at strain rates $10^{-5} \mathrm{~s}^{-1}, 10^{-4} \mathrm{~s}^{-1}$, $10^{-3} \mathrm{~s}^{-1}, 10^{-2} \mathrm{~s}^{-1}$ and $10^{-1} \mathrm{~s}^{-1}$ are plotted in Fig. 13a-e.

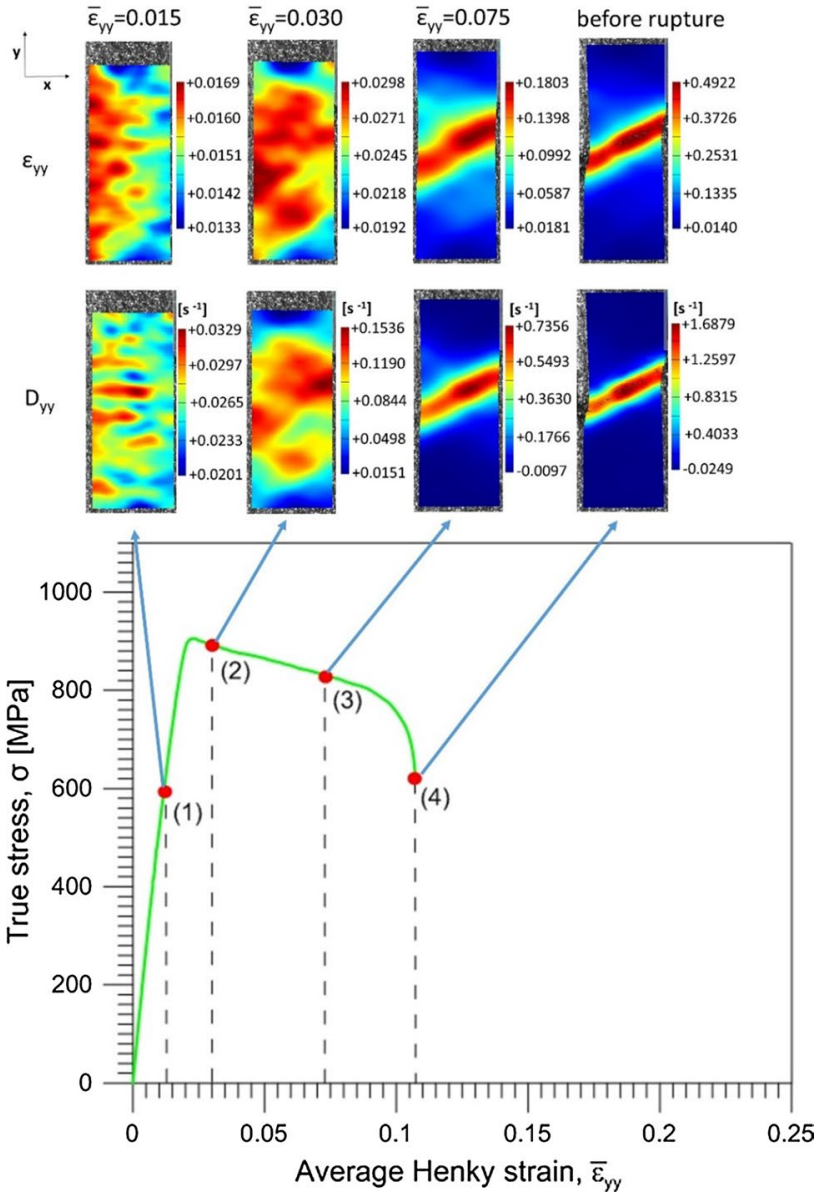

Fig. 11 Distributions of the Hencky strain $\varepsilon_{y y}$ and rate of deformation tensor $D_{y y}$ components of Gum Metal under tension at strain rate of $10^{-1} \mathrm{~s}^{-1}$ at four stages of loading denoted by (1), (2), (3) and (4) 


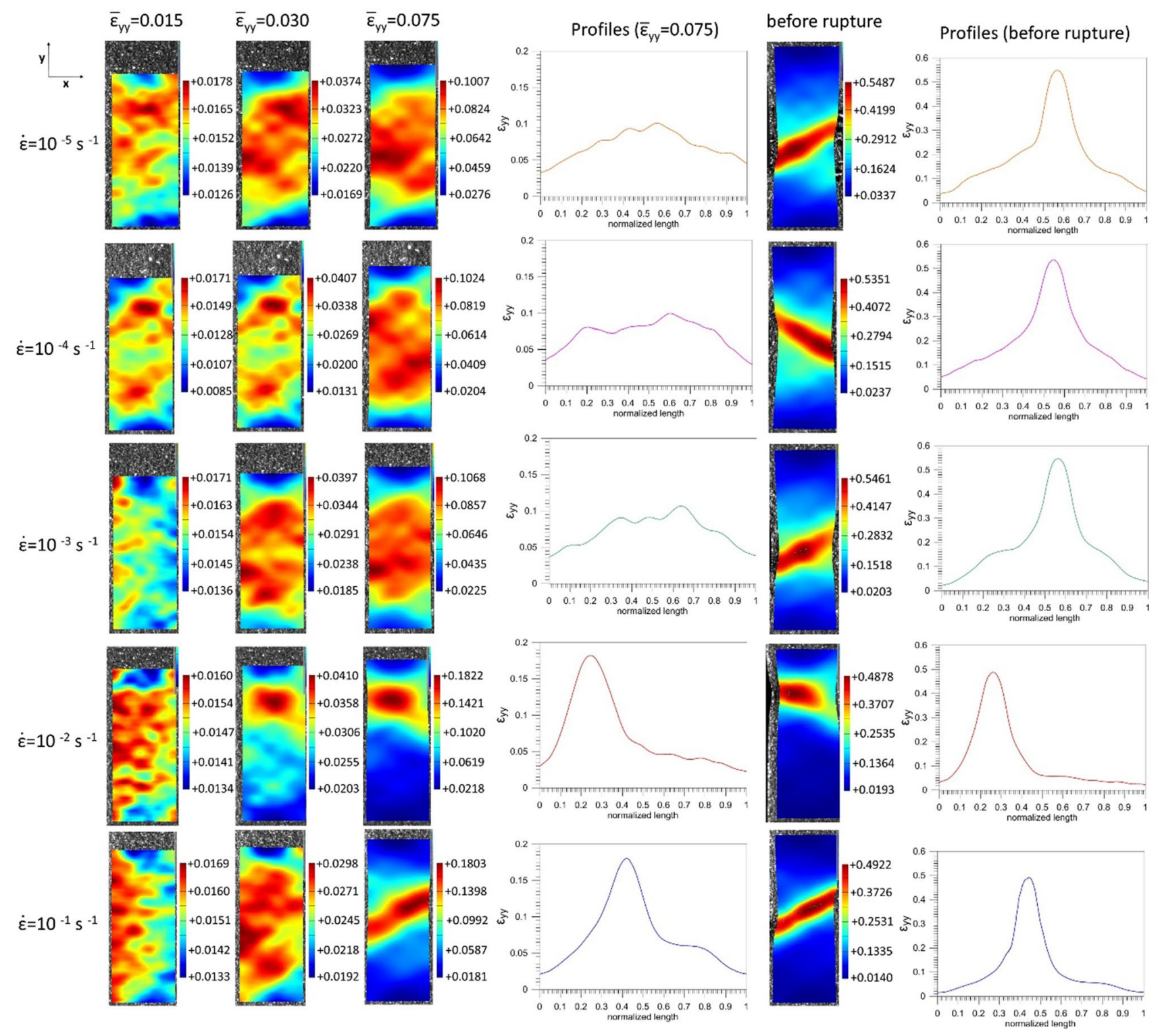

Fig. 12 Development of Hencky strain $\varepsilon_{y y}$ distributions of Gum Metal subjected to tension until rupture at strain rates $10^{-5} \mathrm{~s}^{-1}, 10^{-4} \mathrm{~s}^{-1}$, $10^{-3} \mathrm{~s}^{-1}, 10^{-2} \mathrm{~s}^{-1}$ and $10^{-1} \mathrm{~s}^{-1}$ and selected strain $\varepsilon_{y y}$ profiles

Because of an obvious fact that the tensions at different strain rates have various durations, it is difficult to contrast results presented in Fig. 13a-e. Thus, it is relevant to plot histories of Hencky strain $\varepsilon_{y y}$ versus displacement as plotted in Fig. 14. The records of Hencky strain $\varepsilon_{y y}$ versus displacement show a tendency to grow faster with an increasing strain rate.

\subsubsection{Development of the rate of deformation tensor $D_{y y}$ component distribution}

Distributions of the rate of deformation tensor $D_{y y}$ component for different strain rates are presented in Fig. 15. In addition, profiles passing through a point with maximum values of strain and parallel to the loading direction $y$ are shown on the right of distributions captured at $\bar{\varepsilon}_{y y}=0.075$ and before rupture of Gum Metal.

Similarly to the Hencky strain $\varepsilon_{y y}$ distributions, the deformation rate tensor $D_{y y}$ distributions were approximately the same at strains $\bar{\varepsilon}_{y y}=0.015$ and $\bar{\varepsilon}_{y y}=0.030$ for all strain rates. At strain $\bar{\varepsilon}_{y y}=0.075$, the deformation rate tensor $D_{y y}$ was localized for higher strain rates $10^{-1} \mathrm{~s}^{-1}$ and $10^{-2} \mathrm{~s}^{-1}$ in contrast to the deformation rate tensor $D_{y y}$ distributions for lower strain rates $10^{-3} \mathrm{~s}^{-1}, 10^{-4} \mathrm{~s}^{-1}$ and $10^{-5} \mathrm{~s}^{-1}$. Immediately before rupture of the sample, the rate of deformation tensor $D_{y y}$ distributions was clearly localized in a shear band 
(a)

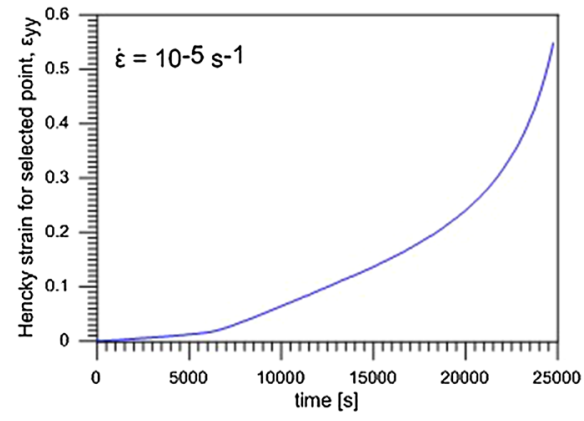

(d)

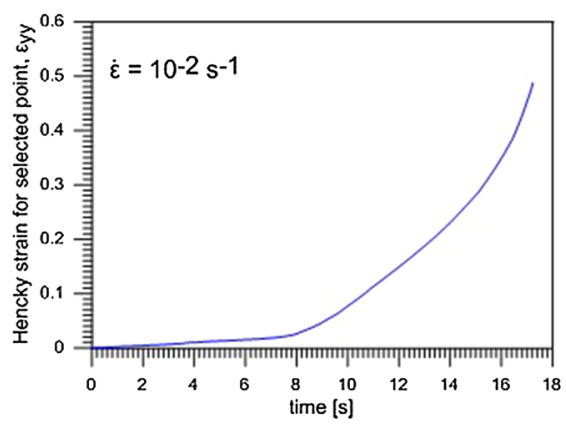

(b)

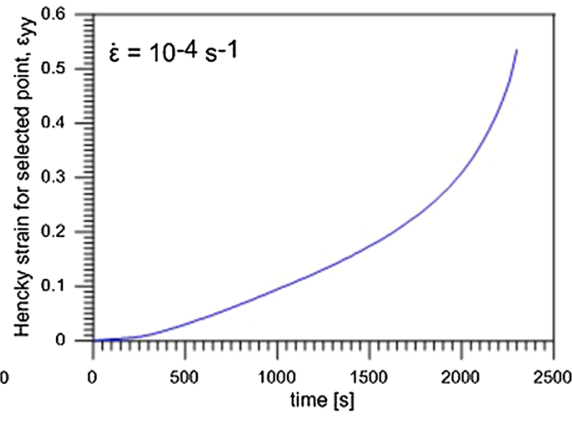

(c)

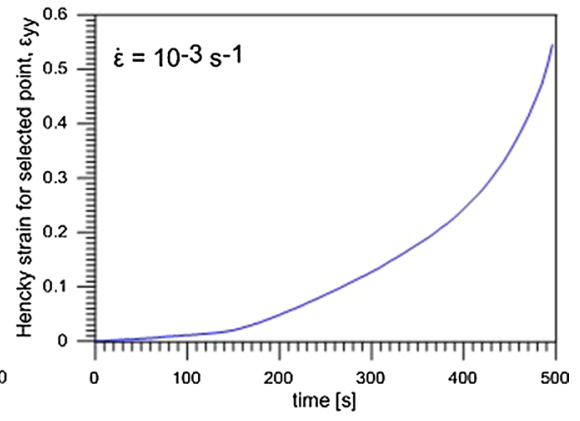

(e)

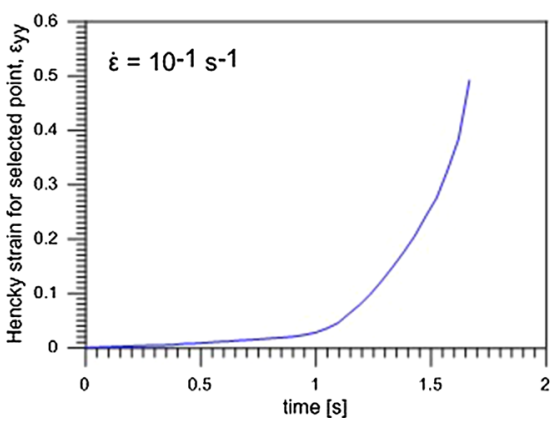

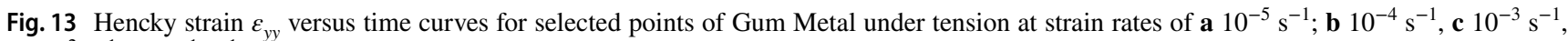
d $10^{-2} \mathrm{~s}^{-1}$, e $10^{-1} \mathrm{~s}^{-1}$

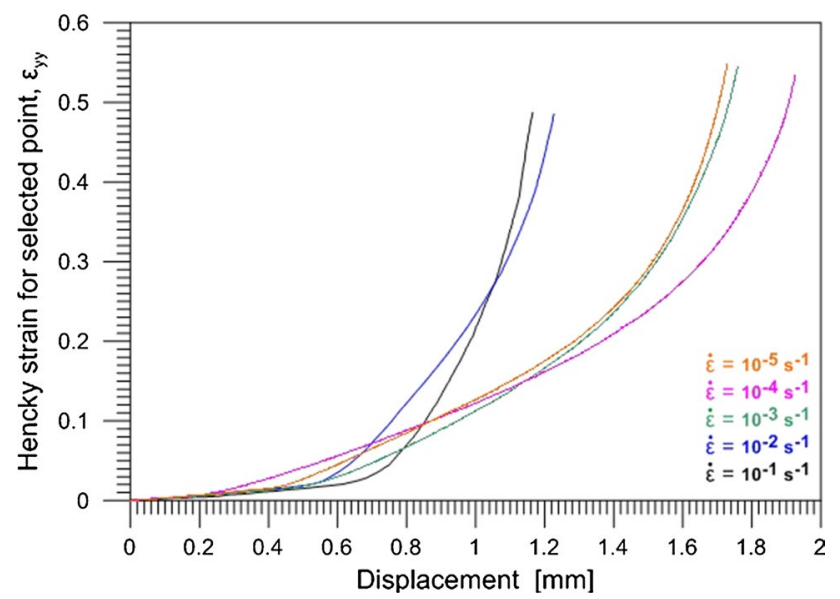

Fig. 14 Hencky strain $\varepsilon_{y y}$ versus crosshead displacement curves for selected points of Gum Metal under tension at five strain rates: $10^{-5} \mathrm{~s}^{-1}, 10^{-4} \mathrm{~s}^{-1}, 10^{-3} \mathrm{~s}^{-1}, 10^{-2} \mathrm{~s}^{-1}$ and $10^{-1} \mathrm{~s}^{-1}$

at all strain rates. Maximum values of local deformation rate $D_{y y}$ were two orders higher when compared to average strain rate values, as shown in the profiles for all strain rates (Fig. 15).

Histories of rate of deformation tensor component $D_{y y}$ versus displacement of selected points with maximal value of rate of deformation tensor component $D_{y y}$ just before rupture for Gum Metal for five strain rates are compared in Fig. 16.

$D_{y y}$ values grow fast in the initial stage of deformation at low displacements for all five strain rates. The maximal values of deformation rate tensor $D_{y y}$ are two orders higher in comparison with average strain rate applied during tension. Maximal Hencky strain $\varepsilon_{y y}$ and deformation rate values for each strain rate are shown in Table 3.

\subsection{Analysis of Gum Metal fracture features}

After Gum Metal tensile loading up to the rupture, the fracture surfaces of selected specimens were observed using JEOL JSM-6480 SEM. The SEM images of the fracture surfaces (fractographs) obtained after tensile tests of Gum Metal at five strain rates $10^{-1} \mathrm{~s}^{-1}, 10^{-2} \mathrm{~s}^{-1}, 10^{-3} \mathrm{~s}^{-1}$, $10^{-4} \mathrm{~s}^{-1}$ and $10^{-5} \mathrm{~s}^{-1}$ are shown in Fig. 17a-e.

The fractographs show mainly ductile features of Gum Metal. As shown in the stress versus strain curves obtained experimentally, the samples underwent a significant amount of elongation before rupture occurred. Many equiaxed dimples are distributed equally and can be seen on the fracture surface of Gum Metal after monotonic tension at highest strain rates applied $10^{-1} \mathrm{~s}^{-1}$ and $10^{-2} \mathrm{~s}^{-1}$. The dimples of fracture surfaces of Gum Metal subjected to monotonic tension at strain rates $10^{-3} \mathrm{~s}^{-1}, 10^{-4} \mathrm{~s}^{-1}$ and $10^{-5} \mathrm{~s}^{-1}$ seem to appear a little larger and deeper. However, no significant 

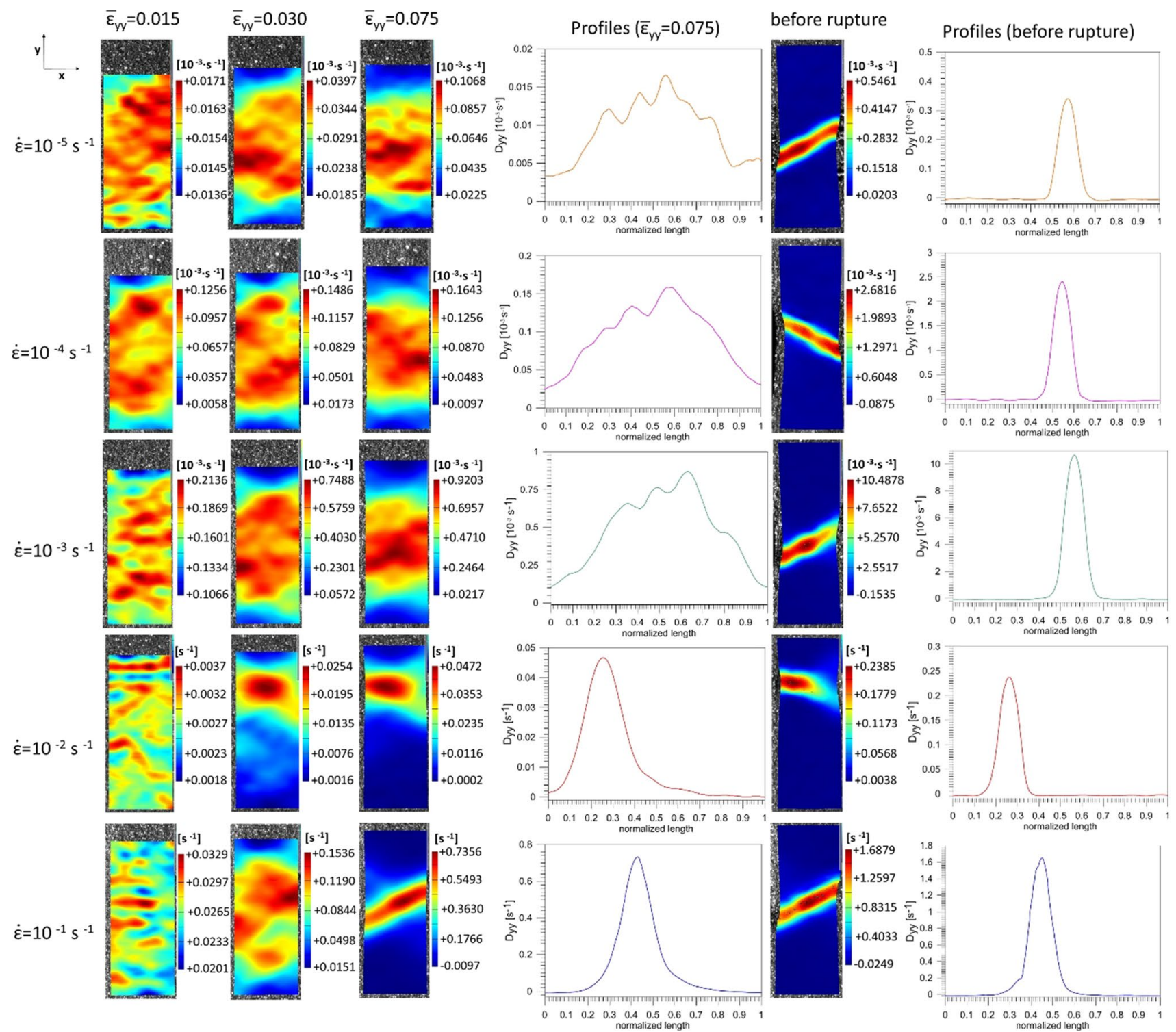

Fig. 15 Development of the rate of deformation tensor $D_{y y}$ distributions at strain rates $10^{-5} \mathrm{~s}^{-1}, 10^{-4} \mathrm{~s}^{-1}, 10^{-3} \mathrm{~s}^{-1}, 10^{-2} \mathrm{~s}^{-1}$ and $10^{-1} \mathrm{~s}^{-1}$ and selected strain $D_{y y}$ profiles

strain rate effect on the analyzed fracture features of Gum Metal is noticed. The observations are in line with results reported in [35] where microstructural features of fracture surfaces in $\mathrm{Ti}-\mathrm{Nb}-\mathrm{Ta}-\mathrm{Zr}$ alloy were discussed and the influence of oxygen content on microstructure evolution with the related mechanical properties was investigated.

\section{Conclusions}

A multifunctional titanium alloy named Gum Metal was investigated by conducting tensile tests at strain rates of $10^{-5} \mathrm{~s}^{-1}, 10^{-4} \mathrm{~s}^{-1}, 10^{-3} \mathrm{~s}^{-1}, 10^{-2} \mathrm{~s}^{-1}$ and $10^{-1} \mathrm{~s}^{-1}$ and applying a field analysis by using DIC technique to discuss subsequent loading and deformation stages of the alloy.

Stress versus strain curves were plotted using two initial lengths of VE ( $7 \mathrm{~mm}$ and $1 \mathrm{~mm})$. The curves confirmed low Young's modulus and high strength of the Gum Metal. The determined values of yield strength had a tendency to increase with increasing strain rates, and the rule "the faster the stronger" was confirmed.

Macroscopically observed work hardening effects were observed for strain rates of $10^{-5} \mathrm{~s}^{-1}, 10^{-4} \mathrm{~s}^{-1}$ and $10^{-3} \mathrm{~s}^{-1}$, whereas softening effects were observed at strain rates of $10^{-2} \mathrm{~s}^{-1}$ and $10^{-1} \mathrm{~s}^{-1}$ in stress versus strain curves plotted using VE $7 \mathrm{~mm}$. Softening phenomena are related to sudden release of energy due to fast development of strain 


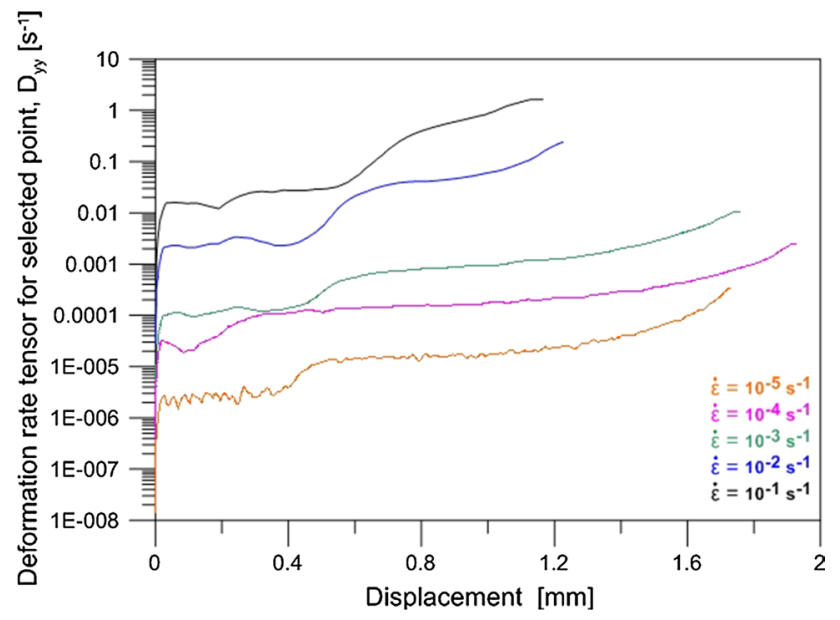

Fig. 16 Deformation rate tensor $D_{y y}$ versus displacement curves for selected points of Gum Metal under tension at five strain rates: $10^{-5} \mathrm{~s}^{-1} ; 10^{-4} \mathrm{~s}^{-1}, 10^{-3} \mathrm{~s}^{-1}, 10^{-2} \mathrm{~s}^{-1}$ and $10^{-1} \mathrm{~s}^{-1}$

Table 3 Maximum $\varepsilon_{y y}$ and $D_{y y}$ for each strain rate

\begin{tabular}{lll}
\hline Strain rate $\left(\mathrm{s}^{-1}\right)$ & $\begin{array}{l}\text { Maximum Hencky } \\
\text { strain } \varepsilon_{y y}\end{array}$ & $\begin{array}{l}\text { Maximum deforma- } \\
\text { tion rate tensor } D_{y y} \\
\left(\mathrm{~s}^{-1}\right)\end{array}$ \\
\hline $10^{-5}$ & 0.5487 & $0.5461 \times 10^{-3}$ \\
$10^{-4}$ & 0.5351 & $2.6816 \times 10^{-3}$ \\
$10^{-3}$ & 0.5461 & $10.4878 \times 10^{-3}$ \\
$10^{-2}$ & 0.4878 & 0.2385 \\
$10^{-1}$ & 0.4922 & 1.6879 \\
\hline
\end{tabular}

localization accumulated during loading at high strain rates. Softening effects were not present in stress versus strain curves plotted using VE $1 \mathrm{~mm}$. The significant difference in the plastic regime of stress versus strain curves plotted using VE $7 \mathrm{~mm}$ and $1 \mathrm{~mm}$ needed an explanation based on analysis of deformation fields.

The values of elongation to the specimen rupture determined from stress versus strain curves plotted for VE $7 \mathrm{~mm}$ tended to decrease with increasing strain rates.

Nucleation and development of strain localization of Gum Metal under tension at various strain rates were demonstrated using DIC technique and analyzed at selected stages of the deformation. The analysis of Hencky strain and rate of deformation tensor component fields demonstrated that at strain rates $10^{-5} \mathrm{~s}^{-1}, 10^{-4} \mathrm{~s}^{-1}$ and $10^{-3} \mathrm{~s}^{-1}$, the deformation is macroscopically uniform up to the average strain $\bar{\varepsilon}_{y y}=0.075$, and at strain rates of $10^{-2} \mathrm{~s}^{-1}$ and $10^{-1} \mathrm{~s}^{-1}$, the strain localization occurs at the earlier stage of the process and is limited to a small area. It was also shown that the values of rate of deformation tensor component $D_{y y}$ grow fast in the initial stage of deformation at low displacements for all five strain rates. The maximal values of $D_{y y}$ are two orders higher in comparison with average strain rate applied during tension.

Fractographic analysis performed on postmortem samples exhibited mainly ductile features, irrespectively of the strain rate applied.
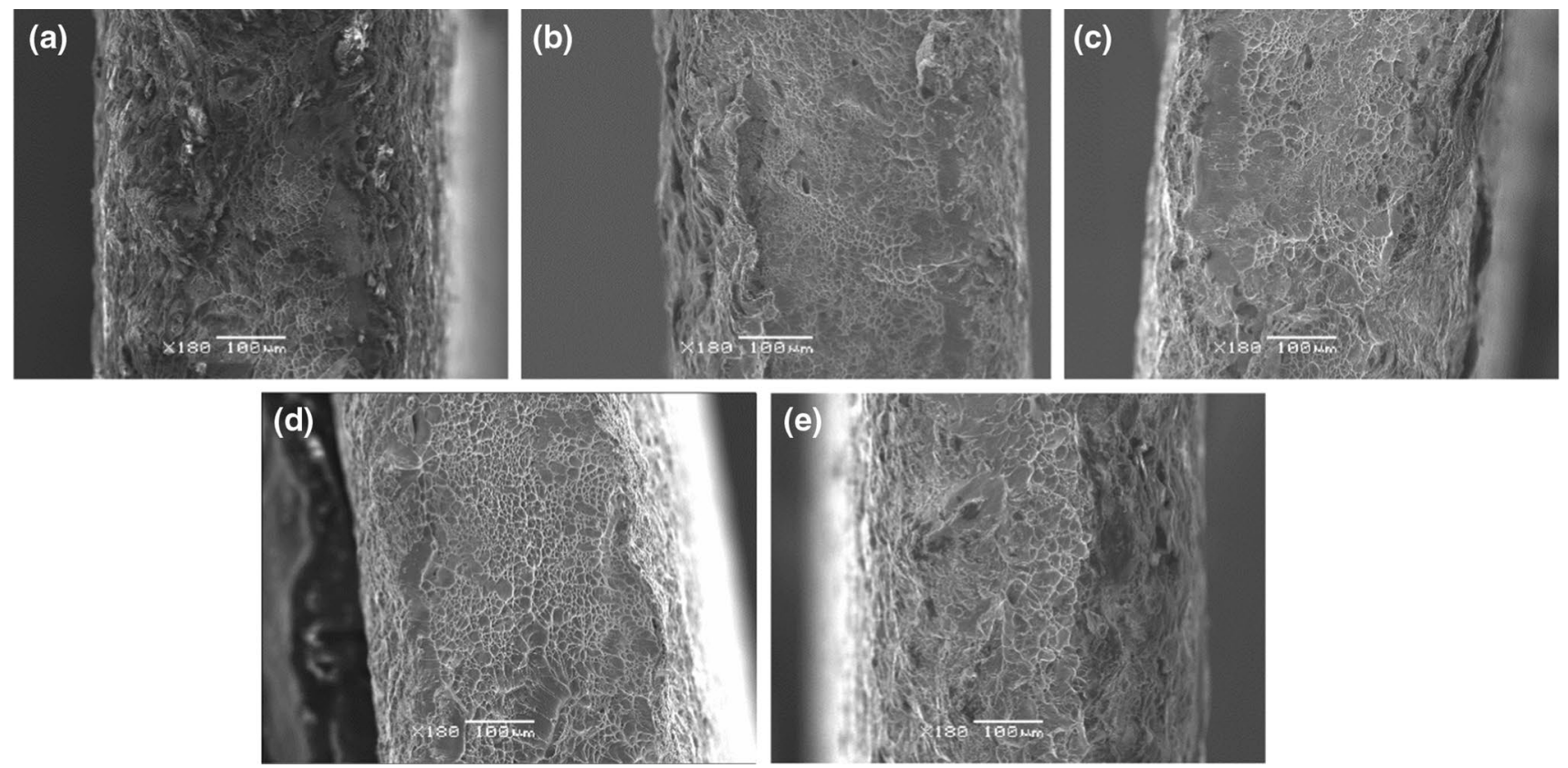

Fig. 17 SEM fractographs of Gum Metal subjected to tension at strain rates of a $10^{-5} \mathrm{~s}^{-1}, \mathbf{b} 10^{-4} \mathrm{~s}^{-1}, \mathbf{c} 10^{-3} \mathrm{~s}^{-1}, \mathbf{d ~} 10^{-2} \mathrm{~s}^{-1}, \mathbf{e} 10^{-1} \mathrm{~s}^{-1}$ 
Acknowledgements The research is partially supported by the Projects of the National Science Centre (NCN), Poland: 2014/13/B/ST8/04280, 2016/23/N/ST8/03688 and 2017/27/B/ST8/03074. The authors would like to express their gratitude to Leszek Urbański for performing experiments and working out mechanical data related to stress versus strain curves.

Open Access This article is licensed under a Creative Commons Attribution 4.0 International License, which permits use, sharing, adaptation, distribution and reproduction in any medium or format, as long as you give appropriate credit to the original author(s) and the source, provide a link to the Creative Commons licence, and indicate if changes were made. The images or other third party material in this article are included in the article's Creative Commons licence, unless indicated otherwise in a credit line to the material. If material is not included in the article's Creative Commons licence and your intended use is not permitted by statutory regulation or exceeds the permitted use, you will need to obtain permission directly from the copyright holder. To view a copy of this licence, visit http://creativecommons.org/licenses/by/4.0/.

\section{References}

1. Saito T, Furuta T, Hwang JH, Kuramoto S, Nishino K, Suzuki N, Chen R, Yamada A, Ito K, Seno Y, Nonaka T, Ikehata H, Nagasako N, Iwamoto C, Ikuhara Y, Sakuma T. Multifunctional alloys obtained via a dislocation free plastic deformation mechanism. Science. 2003;300:464-7.

2. Kuramoto S, Furuta T, Hwang J, Nishino K, Saito T. Elastic properties of Gum Metal. Mater Sci Eng A. 2006;442:454-7.

3. Ikehata H, Nagasako N, Kuramoto S, Saito T. Designing new structural materials using density functional theory: the example of Gum Metal TM. MRS Bull. 2006;31:688-92.

4. Kuramoto S, Furuta T, Hwang JH, Nishino K, Saito T. Plastic deformation in a multifunctional $\mathrm{Ti}-\mathrm{Nb}-\mathrm{Ta}-\mathrm{Zr}-\mathrm{O}$ alloy. Metall Mater Trans A. 2006;37:657-62.

5. Furuta T, Kuramoto S, Morris JW, Nagasako N, Withey E, Chrzan DC. The mechanism of strength and deformation in Gum Metal. Scr Mater. 2013;68:767-72.

6. Wei LS, Kim HY, Koyano T, Miyazaki S. Effects of oxygen concentration and temperature on deformation behavior of $\mathrm{Ti}-\mathrm{Nb}-\mathrm{Zr}-\mathrm{Ta}-\mathrm{O}$ alloys. Scr Mater. 2016;123:55-8.

7. Yano T, Murakami Y, Shindo D, Kuramoto S. Study of the nanostructure of Gum Metal using energy-filtered transmission electron microscopy. Acta Mater. 2009;57:628-33.

8. Coakley J, Vorontsov VA, Littrell KC, Heenan RK, Ohnuma M, Jones NG, Dye D. Nanoprecipitation in a beta-titanium alloy. J Alloys Compd. 2015;623:146-56.

9. Yano T, Murakami Y, Shindo D, Hayasaka Y, Kuramoto S. Transmission electron microscopy studies on nanometer-sized $\omega$ phase produced in Gum Metal. Scr Mater. 2010;63:536-9.

10. Tane M, Nakano T, Kuramoto S, Niinomi M, Takesue N, Nakajima H. $\omega$ Transformation in cold-worked Ti-Nb-Ta-Zr-O alloys with low body-centered cubic phase stability and its correlation with their elastic properties. Acta Mater. 2013;61:139-50.

11. Kim HY, Wei L, Kobayashi S, Tahara M, Miyazaki S. Nanodomain structure and its effect on abnormal thermal expansion behavior of a Ti-23Nb-2Zr-0.7Ta-1.2O alloy. Acta Mater. 2013;61:4874-86.

12. Vorontsov VA, Jones NG, Rahman KM, Dye D. Superelastic load cycling of Gum Metal. Acta Mater. 2015;88:323-33.

13. Plancher E, Tasan CC, Sandloebes S, Raabe D. On dislocation involvement in $\mathrm{Ti}-\mathrm{Nb}$ Gum Metal plasticity. Scr Mater. 2013;68:805-8.

14. Lai MJ, Tasan CC, Raabe D. Deformation mechanism of $\omega$-enriched Ti-Nb-based Gum Metal: dislocation channeling and deformation induced $\omega-\beta$ transformation. Acta Mater. 2015;100:290-300.
15. Lai MJ, Tasan CC, Raabe D. On the mechanism of $\{332\}$ twinning in metastable $\beta$ titanium alloys. Acta Mater. 2016;11:173-86.

16. Castany P, Yang Y, Bertrand E, Gloriant T. Reversion of a parent $\{130\}\langle 310\rangle \alpha^{\prime \prime}$ martensitic twinning system at the origin of $\{332\}$ <113 $\beta$ twins observed in metastable $\beta$ titanium alloys. Phys Rev Lett. 2016;117:245501-1-6.

17. Tane M, Nakano T, Kuramoto S, Hara M, Niinomi M, Takesue $\mathrm{N}$, Yano T, Nakajima H. Low Young's modulus in Ti-Nb-Ta$\mathrm{Zr}-\mathrm{O}$ alloys: cold working and oxygen effects. Acta Mater. 2011;59:6975-88

18. Wei LS, Kim HY, Miyazaki S. Effects of oxygen concentration and phase stability on nano-domain structure and thermal expansion behavior of Ti-Nb-Zr-Ta-O alloys. Acta Mater. 2015;100:313-22.

19. Nagasako N, Asahi R, Isheim D, Seidman DN, Kuramoto S, Furuta T. Microscopic study of gum-metal alloys: a role of trace oxygen for dislocation-free deformation. Acta Mater. 2016;105:347-54.

20. Guo W, Quadir MZ, Moricca S, Eddows T, Ferry M. Microstructural evolution and final properties of a cold-swaged multifunctional Ti$\mathrm{Nb}-\mathrm{Ta}-\mathrm{Zr}-\mathrm{O}$ alloy produced by a powder metallurgy route. Mater Sci Eng A. 2013;575:206-16.

21. Pieczyska EA, Maj M, Furuta T, Kuramoto S. Gum Metal-unique properties and results of initial investigation of a new titanium alloy - extended paper. In: Kleiber M, editor. Advances in mechanics: theoretical, computational and interdisciplinary issues. Balkema/ London: CRC Press/Taylor \& Francis Group; 2016. p. 469-72.

22. Golasiński KM, Pieczyska EA, Staszczak M, Maj M, Furuta T, Kuramoto S. Infrared thermography applied for experimental investigation of thermomechanical couplings in Gum Metal. Quant Infrared Thermogr J. 2017;14:226-33.

23. Pieczyska EA, Maj M, Golasiński K, Staszczak M, Furuta T, Kuramoto S. Thermomechanical studies of yielding and strain localization phenomena of Gum Metal under tension. Materials. 2018;11(567):1-13.

24. Efstathiou C, Sehitoglu H. Local transformation strain measurements in precipitated NiTi single crystals. Scr Mater. 2008;59:1263-6.

25. Daly S, Ravichandran G, Bhattacharya K. Stress-induced martensitic phase transformation in thin sheets of Nitinol. Acta Mater. 2007;55:3593-600.

26. Bewerse C, Gall KR, McFarland GJ, Zhu P, Brinson LC. Local and global strains and strain ratios in shape memory alloys using digital image correlation. Mater Sci Eng A. 2013;568:134-42.

27. Eskandari M, Zarei-Hanzaki A, Yadegari M, Soltani N, Asghari A. In situ identification of elastic-plastic strain distribution in a microalloyed transformation induced plasticity steel using digital image correlation. Opt Laser Eng. 2014;54:79-87.

28. Sène NA, Balland P, Bouabdallah K. Experimental study of Portevin-Le Châtelier bands on tensile and plane strain tensile tests. Arch Civ Mech Eng. 2018;18(1):94-102.

29. Zhang J-L, Tasan CC, Lai ML, Zhang J, Raabe D. Damage resistance in Gum Metal through cold work-induced microstructural heterogeneity. J Mater Sci. 2015;50:5694-708.

30. Liu S, Pan ZL, Zhao YH, Topping T, Valiev RZ, Liao XZ, Lavernia EJ, Zhu YT, Wei Q. Effect of strain rate on the mechanical properties of a Gum Metal with various microstructures. Acta Mater. 2017;132:193-208.

31. Nowak M, Maj M. Determination of coupled mechanical and thermal fields using 2D digital image correlation and infrared thermography: numerical procedures and results. Arch Civ Mech Eng. 2018;18:630-44.

32. Kowalczyk-Gajewska K, Pieczyska EA, Golasiński K, Maj M, Kuramoto S, Furuta T. A finite strain elastic-viscoplastic model of Gum Metal. Int J Plast. 2019;119:85-101.

33. Musiał S, Nowak M, Maj M. Stress field determination based on digital image correlation results. Arch Civ Mech Eng. 2019;19(4):1183-93. 
34. Golasiński K, Pieczyska E, Maj M, Mackiewicz S, Staszczak M, Kowalewski Z, Urbański L, Zubko M, Takesue N. Anisotropy of Gum Metal analysed by ultrasonic measurement and digital image correlation. Mater Sci Technol. 2020;36(9):996-1002.

35. Wei Q, Wang L, Fu Y, Qin J, Lu W, Zhang D. Influence of oxygen content on microstructure and mechanical properties of $\mathrm{Ti}-\mathrm{Nb}-\mathrm{Ta}-$ Zr alloy. Mater Des. 2011;32:2934-9.
Publisher's Note Springer Nature remains neutral with regard to jurisdictional claims in published maps and institutional affiliations. 